\title{
Farinha de carne e ossos na alimentação de larvas de tilápia do Nilo
}

\author{
Meat and bone meal to feed Nile tilapia larvae
}

Arcangelo Augusto Signor $^{{ }^{*}}$ Altevir Signor $^{\mathrm{I}}$ Wilson Rogério Boscolo ${ }^{\mathrm{I}}$ Aldi Feiden ${ }^{\mathrm{I}}$

\section{RESUMO}

No presente trabalho, objetivou-se avaliar a inclusão de farinha de carne e ossos (FCO) na alimentação de larvas de tilápia do Nilo. As dietas foram formuladas de forma a apresentarem-se isoproteicas (38,6\%) e isoenergéticas (3500kcal de $\mathrm{ED} \mathrm{kg}^{-1}$ ), com diferentes níveis de inclusão (0; 5; 10 e 15\%) de FCO. Em um delineamento inteiramente casualizado, foram distribuídas 360 larvas de tilápia $(6,59 \pm 0,02 \mathrm{mg}$ e $0,90 \pm 0,08 \mathrm{~cm})$ em 24 aquários de $30 \mathrm{~L}$. Os peixes foram alimentados até a saciedade aparente às $8 \mathrm{~h}$, $10 \mathrm{~h} 30 \mathrm{~min}, 13 \mathrm{~h}, 15 \mathrm{~h} 30 \mathrm{~min}$ e $18 \mathrm{~h}$, por 30 dias. Ao final do experimento, foram avaliados as médias de peso final (PF), o comprimento final (CF), o comprimento padrão (CP) e a sobrevivência (SO), e os dados foram submetidos à análise de regressão pelo programa SAEG. O nível de inclusão de até $15 \%$ de FCO na dieta não influenciou o peso final das larvas. Entretanto, o maior CP foi observado nas larvas alimentadas com o maior nível de inclusão de FCO na dieta. Portanto, pode ser utilizado o total de até $15 \%$ de inclusão de FCO em rações para larvas de tilápia do Nilo.

Palavras-chave: aquicultura, desempenho, nutrição de peixes, Oreochromis niloticus.

\section{ABSTRACT}

The present study evaluated the inclusion of meat and bone meal (FCO) in Nile tilapia larvae feeding. The diet was formulated to be isoproteic $(38.6 \% \mathrm{DP})$ and isocaloric (3500kcal DE kg-1) with different FCO levels at 0; 5; 10 and 15\%. A 30-day trial was carried out in a complete randomized design with 360 Nile tilapia larvae $(6.59 \pm 0.02 \mathrm{mg}$ and $0.90 \pm$ $0.08 \mathrm{~cm}$ ) distributed in 24 50l-aquaria and fed until satiation five times a day at 8h00,10h30,13h00, $15 \mathrm{~h} 30$ and 18h00. At the end of the experiment the average final weight (PF), final length (CF), standard length (CP) and survival (\%) (SO) were evaluated and the data was submitted to a regression analyses.
The Inclusion level of up to $15 \%$ of FCO in the diet did not influence larvae weight gain. However, the higher CP was observed in larvae fed with the highest level of FCO inclusion in diet. Therefore, it can be used a total of up to $15 \%$ of FCO inclusion in Nile tilapia larvae feeding ration.

Key words: aquiculture, performance, fish nutrition, Oreochromis niloticus.

\section{INTRODUÇÃO}

A aquicultura representa uma fatia significativa na produção de peixes e vem crescendo mais de 8,0\% ao ano (FAO, 2007). Esse crescimento é representado pela intensificação dos sistemas de produção, pelo aumento nas áreas produtivas e pela seleção de espécies que apresentam rápido crescimento, resistência ao manejo, aceitam as mais variadas dietas e proporcionam excelente qualidade de carne. Dessa forma, a tilápia tem se destacado na aquicultura mundial e atualmente representa um dos grupos de peixes mais cultivados no mundo e no Brasil.

As rações utilizadas na aquicultura podem superar 50\% dos custos operacionais de produção (ELSAYED, 1999), tornando-se um dos fatores limitantes para o desenvolvimento da atividade. Em razão da importância da tilápia para aquicultura, muitos aspectos de sua nutrição foram estudados (DEGANI \& REVACH, 1991; BEVERIDGE \& MCANDREW, 2000; LI et al., 2005).

\footnotetext{
'Universidade Estadual do Oeste do Paraná (UNIOESTE), 85903-030, Toledo, PR, Brasil. E-mail: angelo_signor@hotmail.com.
}

*Autor para correspondência. 
Os alimentos de origem animal apresentam alto teor proteico, ácidos graxos, minerais e vitaminas. No entanto, podem apresentar composição variada em proteínas, gorduras, cinzas e aminoácidos, afetando o desempenho dos peixes (PEZZATO et al., 2002). No Brasil, a baixa disponibilidade e o alto custo da farinha de peixe importada impulsionam a busca por novas fontes proteicas em sua substituição que não causem prejuízo ao desenvolvimento dos animais e melhorem o estado de saúde e a resistência dos peixes (BAGNI et al., 2005; GUIMARÃES et al., 2008a).

A substituição das fontes tradicionais de proteína por alimentos alternativos que forneçam proteína a baixo custo é muito importante para o desenvolvimento da cadeia produtiva do pescado (BOSCOLO et al., 2004; GUIMARÃES et al., 2008b), e a utilização de resíduos industriais pode proporcionar outra fonte de agregação de valor à indústria de processamento (FEIDEN et al., 2005).

Dos subprodutos de abatedouro, se destaca a farinha de carne e ossos (FCO), que apresenta elevado teor proteico e é considerada um ingrediente de baixa qualidade quando comparada à farinha de peixe (PEZZATO et al., 2002). A literatura mostra grande variabilidade no conteúdo proteico e na composição aminoacídica desse alimento (POZZA et al., 2004). Segundo esses autores, a FCO apresenta valores de proteína bruta entre 33,53 e $52,43 \%$ e extrato etéreo entre 14,71 e $12,88 \%$. No entanto, FARIA et al. (2002) observaram valores de 37,51 a 41,58\% de proteína bruta para FCO e de 9,25 a $12,25 \%$ de extrato etéreo.

Desta forma, o objetivo do presente trabalho foi avaliar os coeficientes de digestibilidade aparente da energia e proteína da FCO e sua inclusão na alimentação de larvas de tilápia do Nilo.

\section{MATERIAL E MÉTODOS}

O trabalho foi realizado pelo Grupo de Estudos em Manejo na Aquicultura - GEMAq no Laboratório de Aquicultura da Universidade Estadual do Oeste do Paraná/Campus de Toledo. Para avaliar a influência da inclusão da farinha de carne e ossos no desempenho de larvas de tilápia do Nilo (Oreochromis niloticus), previamente foi realizado um ensaio de digestibilidade com a farinha de carne e ossos utilizada no presente experimento para posterior elaboração das rações contendo diferentes níveis de sua inclusão.

O ensaio de digestibilidade foi realizado de acordo com a metodologia descrita por BOSCOLO et al. (2002), e as dietas foram formuladas com base em ingredientes purificados (Tabela 1). Foram utilizados
Tabela 1 - Composição percentual da dieta de referência e da dieta de teste utilizadas para a determinação dos coeficientes de digestibilidade aparente da farinha de carne e ossos.

\begin{tabular}{|c|c|c|}
\hline Ingredientes $(\%)$ & $\begin{array}{l}\text { Ração de } \\
\text { referência }\end{array}$ & $\begin{array}{c}\text { Ração de teste } \\
\text { FCO }\end{array}$ \\
\hline Albumina & 32,00 & 25,60 \\
\hline Gelatina & 7,70 & 6,16 \\
\hline Antioxidante & 0,02 & 0,02 \\
\hline Amido de milho & 44,68 & 35,74 \\
\hline Celulose & 5,00 & 5,00 \\
\hline Fosfato bicálcico & 3,00 & 2,40 \\
\hline Óleo de soja & 6,00 & 4,80 \\
\hline Premix suplementar $(\min .+ \text { vit. })^{1}$ & 1,00 & 1,00 \\
\hline Cloreto de sódio & 0,50 & 0,50 \\
\hline Óxido crômico & 0,10 & 0,10 \\
\hline Alimento de teste & 0,00 & 18,68 \\
\hline Total & 100 & 100 \\
\hline
\end{tabular}

${ }^{1}$ Níveis de garantia por quilograma do produto (Supremais): Vit. A, 1.200.000UI; Vit. $\mathrm{D}_{3}$, 200.000UI; Vit. E, 12.000mg; Vit. K3, $2.400 \mathrm{mg}$; Vit. B1, 4.800mg; Vit. B2, 4.800mg; Vit. B6, 4.000mg; Vit. B12, 4.800mg; Ác. Fólico, $1.200 \mathrm{mg}$; Pantotenato Ca, $12.000 \mathrm{mg}$; Vit. C, $48.000 \mathrm{mg}$; Biotina, $48 \mathrm{mg}$; Colina, $65.000 \mathrm{mg}$; Niacina, 24.000mg; Ferro, $10.000 \mathrm{mg}$; Cobre, $6.000 \mathrm{mg}$; Manganês, 4.000mg; Zinco, 6.000mg; Iodo, 20mg; Cobalto, 2mg; Selênio, $20 \mathrm{mg}$.

quatro aquários circulares de fundo cônico com volume útil de 90L nos quais foram distribuídos ao acaso 80 tilápias de $80,00 \pm 15,97 \mathrm{~g}$. Foi considerado como unidade experimental um aquário contendo 20 peixes. Os animais foram submetidos a um período de adaptação de sete dias para as rações experimentais, e o período de coleta de fezes foi de cinco dias, formando uma amostra composta para cada unidade experimental. As fezes foram congeladas para posteriores análises e cálculos dos coeficientes de digestibilidade aparente da matéria seca, matéria mineral, proteína e energia.

No segundo experimento, para avaliação da inclusão de FCO, os ingredientes selecionados para comporem as dietas experimentais foram moídos em um moinho tipo faca, com peneira de $0,5 \mathrm{~mm}$, e as rações experimentais foram formuladas (Tabela 2 ) com níveis de 0,$0 ; 5,0 ; 10,0$ e $15,0 \%$ de inclusão de farinha de carne e ossos (CO), sendo estas isocalcíticas, isofosfóricas, isoproteicas (38,6\% PD) e isoenergéticas $(3500 \mathrm{Kcal}$ de $\mathrm{ED} \mathrm{kg}^{-1}$ de dieta).

Em um delineamento inteiramente casualizado, foram distribuídas 360 larvas de tilápias do Nilo com peso e comprimento inicial médio de $6,59 \pm 0,02 \mathrm{mg}$ e $0,90 \pm 0,08 \mathrm{~cm}$, respectivamente, em 24 aquários com volume útil de $30 \mathrm{~L}$, constituindo quatro tratamentos e seis repetições, sendo a unidade 
Tabela 2 - Composição percentual e química das dietas experimentais com diferentes níveis de inclusão de farinha de carne e ossos.

\begin{tabular}{|c|c|c|c|c|}
\hline \multirow{2}{*}{ Nutrientes } & \multicolumn{4}{|c|}{ 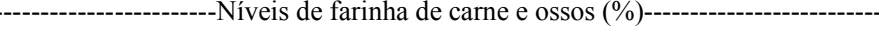 } \\
\hline & 0 & 5 & 10 & 15 \\
\hline Farinha de carne e ossos & 0 & 5,00 & 10,00 & 15,00 \\
\hline Farinha de vísceras de aves & 52,93 & 51,97 & 51,02 & 50,07 \\
\hline Farelo de soja & 26,26 & 24,62 & 22,61 & 20,61 \\
\hline Milho & 5,00 & 5,00 & 5,00 & 5,00 \\
\hline Óleo de soja & 7,09 & 6,99 & 6,89 & 6,80 \\
\hline Fosfato bicálcico & 4,19 & 2,79 & 1,40 & 0,00 \\
\hline Calcáreo calcítico & 1,65 & 1,10 & 0,55 & 0,00 \\
\hline Suplemento (Min.+Vitam.) ${ }^{1}$ & 2,00 & 2,00 & 2,00 & 2,00 \\
\hline Antioxidante & 0,02 & 0,02 & 0,02 & 0,02 \\
\hline Sal comum & 0,50 & 0,50 & 0,50 & 0,50 \\
\hline Total & 100,00 & 100,00 & 100,00 & 100,00 \\
\hline \multicolumn{5}{|l|}{ Nutrientes } \\
\hline Energia digestível $\left(\mathrm{kcal} \mathrm{kg}^{-1}\right)^{2}$ & 3500 & 3500 & 3500 & 3500 \\
\hline Proteína bruta $(\%)$ & 43,66 & 44,48 & 45,30 & 46,12 \\
\hline Proteína digestível $^{2}(\%)$ & 38,60 & 38,60 & 38,60 & 38,60 \\
\hline Gordura (\%) & 13,65 & 13,41 & 13,18 & 12,95 \\
\hline Fibra bruta $(\%)$ & 2,42 & 2,35 & 2,28 & 2,21 \\
\hline Fósforo total (\%) & 2,32 & 2,32 & 2,32 & 2,32 \\
\hline Cálcio (\%) & 3,95 & 3,95 & 3,95 & 3,95 \\
\hline Amido (\%) & 6,71 & 6,44 & 6,17 & 5,90 \\
\hline Metionina + cistina $(\%)$ & 1,80 & 1,81 & 1,83 & 1,85 \\
\hline Metionina (\%) & 0,77 & 0,78 & 0,79 & 0,80 \\
\hline Lisina (\%) & 2,42 & 2,49 & 2,52 & 2,55 \\
\hline
\end{tabular}

${ }^{1}$ Níveis de garantia por quilograma do produto (Rovimix peixes): Vit. A, 500.000UI; Vit. D3, 200.000UI; Vit. E, 5.000mg; Vit. K3, 1.000mg; Vit. B1, 1.500mg; Vit. B2, 1.500mg; Vit. B6, 1.500mg; Vit. B12, 4.000mg; Ác. Fólico, 500mg; Pantotenato Ca, 4.000mg; Vit. C, 15.000mg; Biotina, 50mg; Inositol, 10.000; Nicotinamida, 7.000; Colina, 40.000mg; Co, 10mg; Cu, 500mg; Fe, 5.000mg; I, 50mg; Mn, $1500 \mathrm{mg} ;$ Se, $10 \mathrm{mg} ; \mathrm{Zn}, 5.000 \mathrm{mg}$.

${ }^{2}$ Baseados nos valores de energia e proteína digestível proposto por Boscolo et al. (2002), nos valores propostos por Hayashi et al. (2002) e nos valores determinados por NRC (1993).

experimental considerada como um aquário contendo 15 larvas.

Os aquários consistiam em sistema de aeração individual ligados a um soprador de ar central. Diariamente, foi realizada a sifonagem do fundo dos aquários (8 e 17h), antes da primeira e última alimentação para retirada de sobras de ração e fezes, sendo substituídos cerca de $10 \%$ do volume total de água por vez até o $11^{\circ}$ dia, e posteriormente a renovação foi de $35 \%$. As avaliações físico-químicas da água dos aquários foram realizadas semanalmente, e a temperatura foi mensurada diariamente antes das respectivas sifonagens dos aquários.

Ao final do período experimental, os peixes foram mantidos em jejum por 12 horas; após este período, foram pesados, contados e medidos para os cálculos de peso final médio $(\mathrm{PF})$, comprimento final padrão $(\mathrm{CF})$, comprimento padrão médio $(\mathrm{CP})$ e taxa de sobrevivência (\%) (SO) dos peixes de cada unidade experimental. Os dados obtidos foram submetidos à análise estatística, com 5\% de significância, pelo programa estatístico SAEG (Sistema de Análises Estatísticas e Genéticas) e, em caso de diferenças com nível de 5\%, foi realizada a análise de regressão (UFV, 1997).

\section{RESULTADOS E DISCUSSÃO}

Os parâmetros físico-químicos, como temperatura da água, $\mathrm{pH}$, condutividade elétrica e oxigênio dissolvido nas avaliações de digestibilidade foram $26,76 \pm 0,50^{\circ} \mathrm{C} ; 6,93 \pm 0,40 ; 80,85 \pm 1,21 \mu \mathrm{S} \mathrm{cm}^{-1} \mathrm{e}$ $6,33 \pm 0,34 \mathrm{mg} \mathrm{L}^{-1} \mathrm{e}$, no período experimental de desempenho das larvas, foram de $25,70 \pm 1,17^{\circ} \mathrm{C}$; $8,20 \pm 0,06 ; 91,05 \pm 4,51 \mu \mathrm{S} \mathrm{cm}{ }^{-1} ; 6,44 \pm 0,44 \mathrm{mg} \mathrm{L}^{-1}$,

Ciência Rural, v.40, n.4, abr, 2010. 
respectivamente, permanecendo dentro do recomendado para o cultivo de peixes tropicais (BOYD 1990; SIPAÚBA-TAVARES, 1995).

A composição química da farinha de carne e ossos (CO) (Tabela 3) está dentro da faixa relatada por PEZZATO et al. (2002) e POZZA et al. (2004). Embora sua composição em proteína, extrato etéreo e energia apresentem valores razoáveis do ponto de vista nutricional, a concentração em minerais a torna um ingrediente limitante a ser incluído em dietas para peixes, determinando, dessa forma, os baixos coeficientes de digestibilidade observados para a proteína e energia, o que evidencia sua baixa qualidade nutricional.

Ainda que o nível de proteína bruta da FCO observado no presente experimento seja inferior ao observado por GUIMARÃES et al. (2008b), os resultados são muito parecidos, indicando que, mesmo quando apresenta maiores teores de proteína bruta, a FCO tem limitações para ser utilizada como alimento proteico em dietas para peixes. Em comparação ao farelo de soja e à farinha de peixe, a FCO apresenta baixa disponibilidade dos nutrientes (PEZZATO et al., 2002; GUIMARÃES et al., 2008b).

Entretanto, a inclusão de FCO em baixos níveis pode proporcionar aos peixes uma fonte de minerais de elevada qualidade nutricional (BOSCOLO et al., 2001), principalmente às larvas de tilápia na fase inicial de seu desenvolvimento, as quais apresentam elevado metabolismo e altos índices de crescimento. No entanto, a FCO apresenta um adequado balanço de aminoácidos em sua composição para ser utilizado em dietas para peixes (GUIMARÃES et al., 2008b). A utilização de FCO proporciona bom crescimento em peixes, demonstrando que esse ingrediente apresenta grande valor nutricional, principalmente em relação ao valor biológico da proteína, que melhora a utilização do alimento pelos peixes (EL-SAYED, 1998).

A adição de FCO na dieta das larvas de tilápia não influenciou as respostas de peso final e de sobrevivência das larvas. Entretanto, influenciou

Tabela 3 - Composição química e coeficientes de digestibilidade da farinha de carne e ossos para a tilápia do Nilo.

\begin{tabular}{|c|c|c|c|c|}
\hline \multicolumn{5}{|c|}{ Composição química } \\
\hline MS (\%) & MM (\%) & $\mathrm{PB}(\%)$ & $\mathrm{EE}(\%)$ & $\mathrm{EB}(\mathrm{Kcal} / \mathrm{Kg})$ \\
\hline 91,34 & 31,28 & 46,37 & 12,33 & 3522,35 \\
\hline \multicolumn{5}{|c|}{---------------Coeficientes de digestibilidade (\%)-------------- } \\
\hline & 34,24 & 57,42 & & 59,24 \\
\hline
\end{tabular}

MS - matéria; MM - matéria mineral; $\mathrm{PB}$ - proteína bruta; EE extrato etéreo; EB - Energia bruta. significativamente o comprimento padrão, embora não tenha influenciado o comprimento total das larvas após 30 dias de fornecimento das dietas (Tabela 4). Foi observado aumento linear $(\mathrm{P}<0,05)$ no $\mathrm{CP}$ conforme aumentou a inclusão de FCO. Esses resultados evidenciam uma possível melhora na estrutura óssea das larvas alimentadas com a adição de $15 \%$ de farinha de carne e ossos na dieta.

Mesmo que não tenham sido observadas diferenças $(\mathrm{P}>0,05)$ entre o peso final médio, o comprimento total médio e a sobrevivência das larvas entre os diferentes tratamentos, estes resultados são superiores aos observados por BOSCOLO et al. (2001). Os autores indicam a utilização de 5,0\% de farinha de peixe (FP), farinha de vísceras de aves (FV), farinha de carne e ossos (FCO) ou farinha de crisálida em rações à base de milho e farelo de soja, para promover melhor crescimento dos alevinos de tilápia do Nilo. Resultados semelhantes com a utilização de subprodutos de abatedouro de peixes foram observados por BOSCOLO et al. (2005a). Os autores relatam que a farinha de resíduos da indústria de filetagem de tilápias (FT) pode ser utilizada em rações para larvas de tilápia do Nilo em até $20 \%$ de inclusão. No entanto, para alevinos, BOSCOLO et al. (2005b) indicam a utilização de 13,52\% de FT, sem causar prejuízos no desempenho e na sobrevivência, sendo a FT como uma excelente fonte de aminoácidos e fósforo disponível.

O conhecimento acerca da composição dos subprodutos de origem animal de abatedouros e a influência de sua adição na dieta de peixes pode contribuir para reduzir custos e talvez levar à melhora no desempenho dos peixes cultivados. A relação de nutrientes em sua composição e a disponibilidade destes aos peixes quando de sua inclusão nas dietas podem determinar um melhor balanceamento nutricional das rações, resultando em melhor estado de saúde e maior resistência dos peixes cultivados às adversidades ambientais.

A farinha de carne e ossos utilizada como ingrediente em dietas da tilápia do Nilo, é considerada de baixa qualidade, quando comparada à farinha de vísceras e à farinha de peixe (PEZZATO et al., 2002). Entretanto, apresenta boa composição em minerais, como fósforo e cálcio, de extrato etéreo e energia, e razoável balanço aminoacídico (ALLAN \& ROWLAND, 2005) e baixo custo e elevada disponibilidade (CAMPESTRINI, 2005), a torna um ingrediente de grande interesse a ser utilizado em dietas para peixes, principalmente em razão da grande disponibilidade no Brasil e também da impossibilidade legal do uso em rações para determinados animais, como os bovinos. 
Tabela 4 - Desempenho das larvas de tilápia do Nilo alimentadas com dietas contendo níveis de inclusão de farinha de carne e ossos.

\begin{tabular}{|c|c|c|c|c|c|}
\hline \multirow{2}{*}{ Parâmetros* } & \multicolumn{4}{|c|}{----Níveis de inclusão de farinha de carne e ossos (\%)------- } & \multirow{2}{*}{$\mathrm{CV}(\%)$} \\
\hline & 0 & 5 & 10 & 15 & \\
\hline Peso inicial (mg) & 6,59 & 6,59 & 6,59 & 6,59 & - \\
\hline Peso final (mg) & 1125 & 1138 & 1148 & 1149 & 18,37 \\
\hline Comprimento final total $(\mathrm{cm})$ & 3,87 & 4,01 & 4,09 & 4,11 & 6,99 \\
\hline Comprimento final padrão ${ }^{1}(\mathrm{~cm})$ & $2,98 b$ & $3,13 \mathrm{ab}$ & $3,19 \mathrm{ab}$ & $3,45 \mathrm{a}$ & 8,51 \\
\hline Sobrevivência & 93,33 & 93,33 & 92,22 & 90,00 & 9,47 \\
\hline
\end{tabular}

*Análise de regressão $(\mathrm{P}<0,05)$.

${ }^{1}$ Efeito linear, $(Y=2,9665+0,0747 \mathrm{x}) ; \mathrm{r}^{2}=0,94$.

A substituição da farinha de carne e ossos pelo farelo de soja na dieta melhora o desempenho dos alevinos de carpa capim (Ctenopharyngodon idella), em níveis intermediários de substituição (VEIVERBERG et al., 2008). Os resultados demonstram que, para essa espécie, níveis intermediários de substituição da farinha de carne e ossos $(4,0 \%)$ por farelo de soja $(43,0 \%)$ resultou no melhor desempenho dos peixes. LAZZARI et al. (2006), avaliando diferentes fontes proteicas para juvenis de jundiá, relatam que a combinação de farelo de soja com farinha de carne e ossos ou farinha de peixe proporciona bom desenvolvimento e maior deposição de proteína e gordura no filé.

Os resultados do presente experimento indicam que a farinha de carne e ossos apresenta-se como ingrediente de boa qualidade para ser adicionado na dieta de larvas de tilápia. Os níveis de sua inclusão nas dietas devem levar em conta a sua elevada concentração em minerais e as baixas taxas de disponibilidade de proteína e energia, condição que a torna limitante para ser incluída nas dietas como fonte proteica, mas que poderá contribuir como fonte de minerais aos peixes. Entretanto, novas pesquisas devem ser realizadas para avaliar a possível influência da adição da farinha de carne e ossos na dieta quanto à formação da estrutura óssea e do tecido corporal das larvas de tilápia.

\section{CONCLUSÃO}

Pode ser utilizado o total de até $15 \%$ de inclusão de farinha de carne e ossos em rações para larvas de tilápia do Nilo. O aumento de inclusão de farinha de carne e ossos proporciona aumento no comprimento padrão dos peixes.

\section{REFERENCIAS}

ALLAN, G.L.; ROWLAND, S.J. Performance and sensory evaluation of silver perch (Bidyanus bidyanus Mitchell) fed soybean or meat meal-based diets in earthen ponds. Aquaculture Research, Danvers, v.36, p.1322-1332, 2005. Disponível em: $<$ http://dx.doi.org/10.1111/j.1365-2109.2005.01351.x>. Acesso em: 17 de ago. 2009. doi: 10.1111/j.1365-2109.2005.01351.x.

BAGNI, M. et al. Short- and long-term effects of a dietary yeast $\beta$-glucan (Macrogard) and alginic acid (Ergosan) preparation on immune response in sea bass (Dicentrarchus labrax). Fish \& Shellfish Immunology, v.18, p.311-325, 2005. Disponível em: <http://dx.doi.org/10.1016/ j.fsi.2004.08.003>. Acesso em: 17 de ago. 2009. doi: 10.1016/ j.fsi.2004.08.003.

BEVERIDGE, M.C.M.; McANDREW, B.J. Tilapias: biology and exploitation. Norwell: Kluwer Academic Publishers. 2000. $505 \mathrm{p}$.

BOSCOLO, W.R. et al. Farinhas de peixe, carne e ossos, vísceras e crisálida como atractantes em dietas para alevinos de tilápia do Nilo (Oreochromis niloticus). Revista Brasileira de Zootecnia, v.30, n.5, p.1397-1402, 2001. Disponível em: $<$ http://dx.doi.org/10.1590/S1516-35982001000600002>. Acesso em: 17 de ago. 2009. doi: 10.1590/S151635982001000600002

BOSCOLO, W.R. et al. Digestibilidade aparente da energia e nutrientes de alimentos convencionais e alternativos para a tilápia do Nilo (Oreochromis niloticus, L.). Revista Brasileira de Zootecnia, v.13, n.2, p.539-545, 2002. Disponível em: $<$ http://dx.doi.org/10.1590/S1516-35982002000300001>. Acesso em: 17 de ago. 2009. doi: 10.1590/S151635982002000300001 .

BOSCOLO, W. R. et al. Digestibilidade aparente da energia e proteína das farinhas de resíduo da filetagem da Tilápia do Nilo (Oreochromis niloticus) e da corvina (Plagioscion squamosissimus) e farinha integral do camarão canela (Macrobrachium amazonicum) para a Tilápia do Nilo. Revista Brasileira Zootecnia, v.33, n.1, p.8-13, 2004. Disponível em: <http://dx.doi.org/10.1590/S1516-35982004000100002>. Acesso em: 17 de ago. 2009. doi: 10.1590/S151635982004000100002 .

BOSCOLO, W.R. et al. Farinha de resíduos da filetagem de tilápias na alimentação de tilápia-do-Nilo (Oreochromis niloticus) na fase de reversão sexual. Revista Brasileira Zootecnia. v.34, n.6, p.1807-1812, 2005a. Disponível em: $<$ http://dx.doi.org/10.1590/S1516-359820005000600002>. Acesso em: 17 de ago. 2009. doi: 10.1590/S151635982005000600002 .

Ciência Rural, v.40, n.4, abr, 2010. 
BOSCOLO, W.R. et al. Farinha de resíduos da indústria de filetagem de tilápias como fonte de proteína e minerais para alevinos de tilápia do Nilo (Oreochromis niloticus). Revista Brasileira de Zootecnia, v.34, p.1425-1432, 2005b. Disponível em: <http:// dx.doi.org/10.1590/S1516-35982005000500001>. Acesso em 17 de ago. 2009. doi: 10.1590/S1516-35982005000500001.

BOYD, C. Water quality in ponds for aquaculture. London: Birmingham Publishing, 1990. 482p.

CAMPESTRINI, E. Farinha de carne e ossos. Revista Eletrônica Nutritime, v.2, n.4, p.221-234, 2005.

DEGANI, G.; REVACH, A. Digestive capabilities of three commensal fish species: carp, Cyprinus carpio L., tilápia, Oreochromis aureus $X$ O. niloticus, and African catfish, Clarias gariepinus (Burchel 1822). Aquaculture and Fisheries Management, v.22, p.397-403, 1991. Disponível em: <http:/ /dx.doi.org/10.1111/j.1365-2109.1991.tb00753.x>. Acesso em: 17 ago. 2009. doi: 10.1111/j.1365-2109.1991.tb00753.x.

FARIA, F.D.E. et al. Avaliação da farinha de carne e ossos na alimentação de frangos de corte. Revista Brasileira de Ciência Avícola. v.4, n.1/001, 2002. Disponível em: <http:/ /dx.doi.org/10.1590/S1516-635X2002000100005>. Acesso em: 17 ago. 2009. doi: 10.1590/S1516-635X2002000100005.

EL-SAYED, A.F.M. Alternative dietary protein sources for farmed tilapia, Oreochromis spp. Aquaculture, v.179, p.149168, 1999. Disponível em: <http://dx.doi.org/10.1016/S00448486(99)00159-3>. Acesso em: 17 de ago. 2009. doi: 10.1016/ S0044-8486(99)00159-3.

EL-SAYED, A.F.M. Total replacement of fish meal with animal protein sources in Nile Tilapia, Oreochromis niloticus (L), feeds. Aquaculture Research, v.29, p.275-280, 1998. Disponível em: <http://dx.doi.org/10.1046/j.1365-2109.1998.00199.x>. Acesso em: 17 ago. 2009. doi: 10.1046/j.13652109.1998.00199.x.

FAO - ORGANIZACION DE LAS NACIONES UNIDAS PARA LA AGRICULTURA Y LA ALIMENTACIÓN. El estado mundial de la pesca y la acuicultura 2006. (SOFIA). Roma, 2007. 176p.

FEIDEN, A. et al. Farinha de resíduos da filetagem de tilápia em rações para alevinos de tilápia do Nilo Oreochromis niloticus. Semina Ciências Agrárias, v.26, p.249-256, 2005.

HAYASHI, C. et al. Exigência de proteína digestível para larvas de tilápia do Nilo (Oreochromis niloticus) durante a reversão sexual. Revista Brasileira de Zootecnia, v.31, n.2, p.823828, 2002. Disponível em: <http://dx.doi.org/10.1590/S1516$35982002000400003>$. Acesso em: 17 ago. 2009. doi: $10.1590 / \mathrm{S} 1516-35982002000400003$.
GUIMARÃES, I.G. et al. Nutrient digestibility of cereal grain products and by-products in extruded diets for Nile tilapia. Journal of the World Aquaculture Society, v. 39, n.6, p.781-789, 2008a. Disponível em: <http://dx.doi.org/10.1111/ j.1749-7345.2008.00214.x>. Acesso em: 17 ago. 2009. doi: $10.1111 / \mathrm{j} .1749-7345.2008 .00214 . \mathrm{x}$

GUIMARÃES, I.G. et al. Amino acid availability and protein digestibility of several protein sources for Nile tilapia, Oreochromis niloticus. Aquaculture Nutrition, v.14, p.396404, 2008b. Disponível em: <http://dx.doi.org/10.1111/j.13652095.2007.00540.x>. Acesso em: 17 ago. 2009. doi: 10.1111/ j. 1365-2095.2007.00540.x

LAZZARI, R. et al. Diferentes fontes protéicas para a alimentação do jundiá (Rhamdia quelen). Ciência Rural, v.36, n.1, p.240-246, 2006. Disponível em: <http://dx.doi.org/ 10.1590/S0103-84782006000100037>. Acesso em: 17 ago. 2009. doi: $10.1590 / \mathrm{S} 0103-84782006000100037$.

LI, P. et al. A preliminar study on the effects of dietary suplementation of brewers yeast and nucleotides, singular or in combination, on juvenile red drum (Sciaenops ocellatus). Aquaculture Research, v.36, p.1120-1127, 2005. Disponível em: <http://dx.doi.org/10.1111/j.1365-2109.2005.01333.x>. Acesso em: 17 ago. 2009. doi: $10.1111 / \mathrm{j} .1365$ 2109.2005.01333.x.

NATIONAL RESEARCH COUNCIL. Nutrient requirements of fish. Washington: National Academy, 1993. 114p

PEZZATO, L.E. et al. Digestibilidade aparente de ingredientes pela tilápia do Nilo (Oreochromis niloticus). Revista Brasileira de Zootecnia, v.31, n.4, p.1595-1604, 2002. Disponível em: $<$ http://dx.doi.org/10.1590/S1516-35982002000700001>. Acesso em: 17 ago. 2009. doi: 10.1590/S151635982002000700001 .

POZZA, P.C. et al. Digestibilidade ileal aparente e verdadeira de aminoácidos de farinhas de carne e ossos para suínos. Revista Brasileira de Zootecnia, v.33, n.5, p.1181-1191, 2004. Disponível em: <http://dx.doi.org/10.1590/S1516$35982004000500010>$. Acesso em: 17 ago. 2009. doi: $10.1590 / \mathrm{S} 1516-35982004000500010$.

SIPAÚBA-TAVARES, L.H.S. Limnologia aplicada à aqüicultura. Jaboticabal: Funep, 1995. 72p.

UNIVERSIDADE FEDERAL DE VICOSA. UFV. SAEG Sistema para análises estatísticas e genéticas. Versão 7.1. Viçosa, MG,. 1997. 150p. (Manual do usuário).

VEIVERBERG, C.A. et al. Farelo de soja como substituto à farinha de carne e ossos em dietas para juvenis de carpa capim (Ctenopharyngodon idella). Boletim do Instituto de Pesca, v.34, n.3, p.463-472, 2008. 